\title{
What Else Is Needed in the Korean Government's Master Plan for People With Developmental Disabilities?
}

\author{
Jin Yong Lee ${ }^{1,2}$, Jieun Yun ${ }^{3}$ \\ 'Department of Public Health and Community Medicine, Seoul Metropolitan Government-Seoul National University (SMG-SNU) Boramae Medical \\ Center, Seoul, Korea; ${ }^{2}$ Department of Health Policy and Management, Seoul National University College of Medicine, Seoul, Korea; ${ }^{3}$ Department of \\ Pharmaceutical Engineering, Cheongju University, Cheongju, Korea
}

On September 12, 2018, President Jae-In Moon announced the Comprehensive Plan for Lifelong Care for People with Developmental Disabilities, with representatives from the associated government branches (Ministry of Health and Welfare, Ministry of Education, and Ministry of Employment and Labor) in attendance. The goals of this plan are to provide health, medical, rehabilitative, special education, and social welfare services according to the life-stages of the affected individuals; to reduce parental pressure; to promote social interventions; and to enhance community-level participation in order to create a'welfare society in harmony'. However, in order for the plan to succeed, additional efforts must be made in the following areas. First, an epidemiological survey is needed to understand the scale, prevalence, and incidence of developmental disabilities and to establish an evidence base to support policy development. Second, accurate definitions of developmental disabilities must be established in order to avoid policy discrimination based on impairment type and age. Third, personal evaluations to assess disabled individuals' unmet needs and customized service designs to deliver those needs are required. Fourth, the plan must fulfill the goals of accessibility and fairness that the government intends to provide. Fifth, the government should consider an integrated financial support system and to propose a detailed plan for monetary distributions. Finally, an integrated system that links health, medical, employment, educational, and welfare services must be constructed.

Key words: Developmental disability, Autistic spectrum disorder, Intellectual disability, Prevalence, Incidence, Comprehensive health care

The term 'developmental disability' in South Korea (hereafter Korea) encompasses both intellectual disabilities and autism spectrum disorder (ASD); these disabilities require specialized

Received: October 25, 2018 Accepted: May 7, 2019

Corresponding author: Jin Yong Lee, MD, PhD

Department of Public Health and Community Medicine, Seoul Metropolitan Government-Seoul National University (SMG-SNU) Boramae Medical Center, 20 Boramae-ro 5-gil, Dongjak-gu,

Seoul 07061, Korea

E-mail: jylee2000@gmail.com

This is an Open Access article distributed under the terms of the Creative Commons Attribution Non-Commercial License (http://creativecommons.org/licenses/by$\mathrm{nc} / 4.0 / /$ which permits unrestricted non-commercial use, distribution, and reproduction in any medium, provided the original work is properly cited. social support, as they start early in children's lives and continue as they grow $[1,2]$. If parents of disabled children were to exclusively assume all responsibilities for child-rearing, they would be forced into a state of poverty as they would not be able to maintain stable jobs, and they also would become perpetually restless due to the inability to escape from their lifelong duties $[3,4]$. As portrayed in the media from time to time, extreme circumstances can even drive parents to murder their own disabled children and to commit suicide themselves [5].

September 12, 2018, will be remembered as a meaningful day for individuals with developmental disabilities and their families because President Jae-In Moon announced the Comprehensive Plan for Lifelong Care for People with Develop- 
mental Disabilities, with representatives from the associated branches of the government (Ministry of Health and Welfare, Ministry of Education, and Ministry of Employment and Labor) in attendance. The goals of this comprehensive plan are to provide health, medical, rehabilitative, special education, and social welfare services according to the life-stages of the affected individuals; to reduce parental pressure; to promote social interventions; and to enhance community-level participation in order to create a'welfare society in harmony' [1].

The discussion of the current plan was sparked by an appalling incident that shocked our society on September 5, 2017, when parents of disabled children kneeled to beg local residents to reconsider opposing the establishment of a special education school in the area [1,2]. The entire nation witnessed the dreadful circumstances that disabled children and their parents must face in our society through this incident. Developmental disabilities are categorized as severe because they often manifest through significant deficiencies in cognitive and communication skills, rendering independent living an impossibility and special education a quintessential necessity for the affected individuals [3-7]. Therefore, those parents were determined to persuade the local residents, even by kneeling to beg them to reconsider their opposition, in the hopes of establishing a special education school for their children [6].

The aim of this article is to evaluate the president's proposed plan for individuals with developmental disabilities and to explore areas that have been overlooked or require further attention. It is probable that the suggested problems and alternative solutions overlap with other types of disabilities. However, we intend to focus on developmental disabilities, as this topic was our primary motivation for writing this article. Previous government policies on disabled individuals were segmented and not evidence-based, and also had a tendency to react to demands of recipients rather than to reflect a needbased prioritization. We evaluate the current policy positively, and believe it will serve as an important turning point for future policy-making processes regarding disabled individuals because of its attempt to provide necessary health, medical, educational, and welfare services according to the affected individuals' life-stages and its careful approach to assessing and prioritizing recipients [1].

As a foreign case study related to the current policy, we should take a closer look at the recent changes made in Medicaid in the USA. Medicaid resembles the medical benefits available in Korea, as its main beneficiaries are low-income families. However, recent policy changes in Medicaid have expanded its coverage to individuals diagnosed with ASD for a given period of time to prevent the cost of treatment from impoverishing middle-class families. In addition, Medicaid has recognized the revised Diagnostic and Statistical Manual of Mental Disorders (DSM-5) published by the American Psychiatric Association, which expanded the category of ASD, and has coped with the spike in the number of diagnosed ASD cases following this revision. Furthermore, it has broadened its coverage to include social welfare services and special education, as well as medical services. The fact that even the USA, where healthcare is largely privatized, provides medical services, special education, and social welfare to individuals with ASD via Medicaid is highly significant for our society [3,7-9].

In the rest of this article, we would like to focus on important points that are still missing or overlooked in the current government policy. We will also suggest several items, including lessons learned from Medicaid, that are necessary for the success of the policy.

First, an epidemiological study is needed to accurately identify the scale, prevalence, and incidence of developmental disabilities and to establish an evidence base for policy development.

The most important aspect in developing and implementing a policy is to assess the scale of recipients who would benefit from the policy. In other words, it is necessary to identify the number of individuals currently affected by certain problems and to predict the number that will be affected in the future. To phrase this point using epidemiological terminology, we need to accurately identify the prevalence and incidence of the disease. According to data from the Ministry of Health and Welfare, a total of 226000 individuals had developmental disabilities in 2018, with 201000 cases of intellectual disabilities (88.9\%) and 25000 cases of ASD (11.1\%). By age group, 47000 (20.8\%) infants and children, 170000 adults (75.2\%), and 9000 seniors over 65 years of age were affected by these disabilities, and the numbers are increasing by $3.6 \%$ annually [1]. It is likely that the government utilized these data to assess the estimated costs of policy development and implementation. However, we would like to point out that the identified total scale of developmental disabilities is likely to be an underestimation, and the current form of data collection is inadequate for accurately calculating the prevalence and incidence. 
Table 1. Total scale of developmental disabilities from different database

\begin{tabular}{lrcc}
\hline Age (y) & $\begin{array}{c}\text { Disability } \\
\text { Registry } \\
\text { (2017) }\end{array}$ & $\begin{array}{c}\text { The National Survey } \\
\text { on Persons with } \\
\text { Disabilities (2014) }\end{array}$ & $\begin{array}{c}\text { National Health } \\
\text { Insurance } \\
\text { Service (2017) }\end{array}$ \\
\hline Total & 24698 & 18951 & 19295 \\
$0-9$ & 5509 & 3183 & 8150 \\
$10-19$ & 9572 & 9482 & 6348 \\
$20-29$ & 7935 & 6286 & 3936 \\
$30-39$ & 1467 & 0 & 745 \\
$40-49$ & 179 & 0 & 76 \\
$50-59$ & 28 & 0 & 30 \\
$60-69$ & 7 & 0 & 5 \\
$70-79$ & 1 & 0 & 5
\end{tabular}

Currently the three reliable statistical sources on the total scale of developmental disabilities are the Disability Registry database (DB), the National Survey on Persons with Disabilities DB, and the National Health Insurance Service (NHIS) DB. Among these sources, the government bases its policies on the Disability Registry DB. The National Survey on Persons with Disabilities DB provides an estimate from sampling surveys, while the NHIS DB computes the number of treatments rendered for developmental disabilities. In order to accurately assess the scale of developmental disabilities, a comparative analysis of the three data sources is very important because they can complement each other. In our analysis of the total scale of developmental disabilities, we discovered the following findings (Table 1).

First, the number of individuals with developmental disabilities drastically decreased after the age of 30 , and there were scarcely any individuals with ASD over the age of 50 . The National Survey on Persons with Disabilities DB even reported that the estimated number of individuals with ASD over the age of 30 was zero. We suggest that these values are gross underestimations because this trend was only observed for ASD, and not for the other 15 types of disabilities. ASD has been with humankind for a long time. Assuming the incidence of the disease remains constant, how can we explain the observation that the number of afflicted individuals diminished radically after the age of 30 ? Estimating the incidence from the 10-year-old to 19-year-old intervals in the Disability Registry DB, we can assume that about 1000 newborns have ASD in any particular year. If we assume that the death rate of afflicted newborns is similar to that of other populations, we would expect to see about 7000-9000 disabled individuals in each of the age intervals between 30 years and 39 years old, 40 years and 49 years old, and 50 years and 59 years old. Therefore, further research is necessary to evaluate the accuracy of the current data on the number of individuals with developmental disabilities. If the data are proven to be accurate, we must explain this phenomenon. This kind of problem has not been reported for other types of disabilities. Therefore, we must not forget that the most important aspect of implementing a policy is to obtain an accurate estimation of the number of individuals with developmental disabilities.

Second, despite the vital importance of prevalence and incidence data in implementing healthcare policies, no nationwide survey to estimate the prevalence and incidence of developmental disabilities has been conducted. Because disability registration is available after the age of 3 and most diagnoses are made before children start their primary education, prevalence and incidence should be surveyed through a 7-year to 10-year follow-up study of birth cohorts from different calendar years. In short, although the need for academic and empirical evidence to support the development and implementation of policy is clear, too few areas have been properly studied to find evidence for policy implementation. As mentioned above, further research on developmental disabilities is necessary on subjects such as the total scale, prevalence, incidence, suicide rate, morbidity and mortality rate, accident rate, nationwide distribution, composition of early treatment facilities, current usage of medical facilities, and disparities in access near the Seoul metropolitan area. Additionally, construction of birth cohorts using the Disability Registry DB, Survey of Disability DB, and NHIS DB is the most important method for identifying unknown aspects of these disabilities.

Second, impairments associated with developmental disabilities must be accurately defined, and unintended policy discrimination based on the type of impairment and age must be avoided.

Although the term 'developmental disability' in government policies represents both intellectual disabilities and ASD, these types of disorders have sharply distinct characteristics. The lack of a clear distinction between these two types of impairments has not yet caused any debates, but there still is a possibility for controversy depending on future government policies. For example, Medicaid expanded its coverage of ASD after the recent revision of the DSM- 5 and now covers applied behavior analysis (ABA) for individuals with ASD, which has led to an increase in number of individuals with the disorder 
[3,7-9]. Let us suppose that Korea implements a similar policy, only covering individuals with ASD and prioritizing the population under the age of 7 who would have better treatment outcomes. In such a case, individuals with intellectual disabilities would be tempted to change their impairment status due to their lack of access to such services. Additionally, further disputes would be expected, even in individuals with ASD, because people outside of this age range would not benefit from the policy. In addition, if new evidence-based services are implemented with a fixed total budget to be spent on developmental disabilities, the majority of the budget will be allotted to the new services, which could result in the inadvertent side effect of a reduced budget for previously existing services. Because a similar case already happened when coverage for individuals with hearing impairments expanded to include cochlear implants and verbal remediation therapy, the government policy must be flexible enough to avoid such side effects.

Third, unmet needs should be assessed via personal evaluations of individuals with developmental disabilities and customized services should be designed based on those assessments.

According to the announced policy, an individual with a developmental disability can benefit from a service only after she identifies her own needs and applies for it. However, an ideal approach would be to have the government provide integrated services based on a personal evaluation of the individual. That is, customized services should be designed and provided to individuals after identifying their specific needs for healthcare, medicine, rehabilitation, special education, job education, and social welfare. An organization more extensive than the Disability Class Decisions Committee is needed. This organization should include healthcare professionals such as doctors, nurses, and other professionals from related fields such as special education, social welfare, and job rehabilitation, and it should be responsible for making yearly judgments on services that would accommodate an individual's specific needs and for providing the services to the beneficiaries.

Fourth, the accessibility and fairness of the services provided must be considered.

There should be no difference in the quality and quantity of services provided by the government throughout the country. The government should focus on preventing any disparities in access according to household income. The availability of health, medicine, rehabilitation, special education, and so- cial welfare services must not exhibit any regional disparities. Special care must be taken to avoid such problems in rural areas when compared to the urban regions. Along with equality in quantitative distribution, the quality of services must be comparable in all areas. According to a recent study on palliative and hospice care for pediatric patients with rare incurable diseases, only two general hospitals in Seoul, out of all general hospitals in the country, had sufficient resources to provide proper services [10]. Such disparities can also occur in the provision of services to individuals with developmental disabilities.

Fifth, the government must consider an integrated financial support system to systematically provide health, medicine, education, and social welfare services and propose a detailed financial plan for budget distributions.

The fact that even the USA, where healthcare is largely privatized, provides not just medical services, but also coverage for ABA, special education, and social services to individuals with ASD via Medicaid is highly significant. To prevent treatment costs from pushing middle-class families into poverty, Medicaid classifies individuals with ASD as beneficiaries regardless of their income. It has also approved the expanded diagnostic criteria of ASD in the DSM-5 and coped with the sudden spike in the number of diagnosed ASD cases. A recognition of the need for an integrated financial support system to provide not just medical services, but also other follow-up services such as behavioral therapy, special education, and social welfare services, drove those changes [3,7-9]. Korea will have to consider a similar integrated financial support system in the long run. In addition, the current policy does not specify an approximate total budget or a plan for its distribution. Therefore, further specifications are necessary.

Sixth, an integrated system that links health, medicine, employment, education, and social welfare services must be constructed.

Health, medical, educational, and social welfare services for individuals with developmental disabilities must be delivered in an integrated manner. However, it is highly likely that our current system will only allow for segmented support services that are scattered across different government branches such as the Ministry of Health and Welfare, Ministry of Education, and Ministry of Employment and Labor. Therefore, even if each branch of government works independently to provide its own services, an integrated system must be established to oversee the different types of services provided to individuals 
with disabilities.

Above, we have listed several overlooked agenda items related to this policy and suggested our perspectives on how these issues should be resolved. We believe that many of our suggestions are applicable not only to policies regarding developmental disabilities, but also to those regarding other disabilities. It is our hope that the current government policy serves as a significant turning point for future policies regarding developmental disabilities and also as another step towards a'welfare society in harmony.'

\section{SUPPLEMENTAL MATERIALS}

Korean version is available at https://www.jpmph.org/.

\section{CONFLICT OF INTEREST}

The authors have no conflicts of interest associated with the material presented in this paper.

\section{ACKNOWLEDGEMENTS}

The authors of this article, Jing Yong Lee and Jieun Yun, are parents of a child with a developmental disability.

\section{ORCID}

Jin Yong Lee http://orcid.org/0000-0002-7752-2697

Jieun Yun http://orcid.org/0000-0002-4241-4274

\section{REFERENCES}

1. Ministry of Health and Welfare. Announcement of comprehensive plans for lifelong care for people with developmental disabilities; 2018 Sep 12 [cited 2018 Sep 20]. Available from: http://www.mohw.go.kr/react/al/sal0301vw.jsp?PAR_MENU_ ID $=04 \& M E N U \_I D=0403 \& C O N T \_S E Q=346056 \&$ page $=1($ Ko- rean).

2. Barrett B, Mosweu I, Jones CR, Charman T, Baird G, Simonoff E, et al. Comparing service use and costs among adolescents with autism spectrum disorders, special needs and typical development. Autism 2015;19(5):562-569.

3. Leslie DL, Iskandarani K, Velott DL, Stein BD, Mandell DS, Agbese $\mathrm{E}$, et al. Medicaid waivers targeting children with autism spectrum disorder reduce the need for parents to stop working. Health Aff (Millwood) 2017;36(2):282-288.

4. Buescher AV, Cidav Z, Knapp M, Mandell DS. Costs of autism spectrum disorders in the United Kingdom and the United States. JAMA Pediatr 2014;168(8):721-728.

5. Shin YA. 40s father, suicide after killing 10 teen autistic son. Seoul Shinmun; 2013 Dec 3 [cited 2018 Sep 20]. Available from: http://mnm5.seoul.co.kr/news/newsView.php?id=20131203008019\&spage $=99$ (Korean).

6. Jung YS. Parents kneeling for permission to establish a school for disabled students "Do not show!" an inhabitant. SBS News; 2017 Sep 7 [cited 2018 Sep 20]. Available from: https://news. sbs.co.kr/news/endPage.do?news_id=N1004384095 (Korean).

7. Maglione M, Kadiyala S, Kress A, Hastings JL, O'Hanlon CE. TRICARE applied behavior analysis (ABA) benefit: comparison with Medicaid and commercial benefits. Rand Health Q 2017; 6(2): 10 .

8. Bowen SE. Autism spectrum disorders (ASD): state of the states of services and supports for people with ASD; 2014 [cited 2018 Sep 20]. Available from: https://www.medicaid.gov/medicaid/ Itss/downloads/asd-state-of-the-states-report.pdf.

9. Velott DL, Agbese E, Mandell D, Stein BD, Dick AW, Yu H, et al. Medicaid 1915(c) Home- and Community-Based Services waivers for children with autism spectrum disorder. Autism 2016;20(4):473-482.

10. Kim MS, Lim NG, Kim HJ, Kim C, Lee JY. Pediatric deaths attributed to complex chronic conditions over 10 years in Korea: evidence for the need to provide pediatric palliative care. J Korean Med Sci 2018;33(1):e1. 